\title{
Papers
}

\section{Inequalities in access to diabetes care: evidence from a historical cohort study}

\author{
Elizabeth C Goyder, Paul G McNally, Johannes L Botha
}

Department of Epidemiology and Public Health, University of Leicester, 22-28 Princess Road

West, Leicester LE1 6TP, UK E C Goyder, $M R C /$ Trent training fellow in health services research Johannes L Botha, senior lecturer in epidemiology

Department of Diabetes and Endocrinology, Leicester Royal Infirmary NHS Trust, Leicester LE1 5WW, UK

Paul G McNally, consultant physician

Correspondence to: Dr E Goyder, School of Health and Related Research (ScHARR), University of Sheffield, Regent Court, 30 Regent Street, Sheffield S1 4DA, UK

email:

e.goyder@sheffield.ac.uk

Accepted 13 March 2000

\begin{abstract}
Objective-To establish which factors predict attendance at a hospital diabetes clinic and for diabetes review in general practice.

Design-A historical cohort study of individuals with diabetes identified from general practice records. Information on service contacts and other clinical, social, and demographic variables was collected from general practice records and postal questionnaires.

Setting-Seven Leicestershire general practices.

Subjects-Individuals registered with study practices who had a diagnosis of diabetes made before 1990 .

Main outcome measurementsAttendance at a hospital diabetes clinic or for a documented diabetes review in general practice at least once between 1990 and 1995.

Results-124 (20\%) had at least one recorded diabetes review in general practice and $332(54 \%)$ attended a hospital diabetes clinic at least once. The main predictors of attending a hospital clinic were younger age, longer duration of diabetes, and treatment with insulin. Access to a car (OR 1.34, 95\% CI 1.06 to 1.71), home ownership (OR 1.48, 95\% CI 1.14 to 1.58 ) and a non-manual occupation (OR 1.56, 95\% CI 1.09 to 2.24 ) were all associated with an increased likelihood of attending, although living in a less deprived area was not. The main predictors of attending for review in general practice were older age, less co-morbidity, and being white. Living in a more deprived area was related to a reduced chance of review in general practice (OR $0.81,95 \%$ CI 0.76 to 0.86 ) while individual socioeconomic indicators were not.

Conclusions-Whilst an indicator of area deprivation predicts reduced likelihood of review in general practice, individual indicators predict reduced likelihood of attending outpatients. This suggests a need for different approaches to tackling inequalities in access to care in primary and secondary care settings. (Quality in Health Care 2000;9:85-89)
\end{abstract}

Keywords: diabetes mellitus; access to care; general practice; outpatient clinic

Once diabetes has been diagnosed, an individual's risk of developing serious microvascular and macrovascular complications of diabetes over time can be significantly reduced by early identification and treatment of risk factors. In particular, long term complications can be reduced by early and effective treatment of hyperglycaemia, hypertension, and early diabetic eye disease. ${ }^{12}$ Although effective evidence based interventions are available, these conditions are generally not symptomatic so a cornerstone of good quality diabetes care is regular clinical review to detect problems that would benefit from intervention.

It has been well documented in the past that a sizeable proportion of individuals with a diagnosis of diabetes are not seen at all in hospital diabetes clinics, particularly if they do not require treatment with insulin..$^{3-5}$ Some of these individuals are seen regularly in primary care, often in clinics run by practice nurses or general practitioners (GPs). However, a significant proportion are not routinely reviewed at all. ${ }^{6}$ This group of patients includes some who will later present with complications who might have benefited from earlier intervention. Although a causal association cannot be proved, development of nephropathy has previously been shown to be associated with a lower rate of attendance at a hospital clinic.

There is considerable evidence from other conditions, particularly cardiovascular disease, that access to services is related to relative affluence or deprivation. ${ }^{8}$ There is evidence that socioeconomic factors influence access to care in many different populations and within different health services. ${ }^{10}$ The evidence for inequalities in access to health care in the UK has recently been reviewed. ${ }^{11}$ In studies of diabetic clinic populations it has been shown that morbidity is related to socioeconomic factors $^{12}{ }^{13}$ and that deprivation is related to poorer diabetic control and less insulin use. ${ }^{14} 15$ However, it is likely that these cohorts are not representative of all individuals with diabetes since they represent those already attending clinics. It is therefore important also to study populations which include individuals with diabetes who do not attend hospital clinics and 


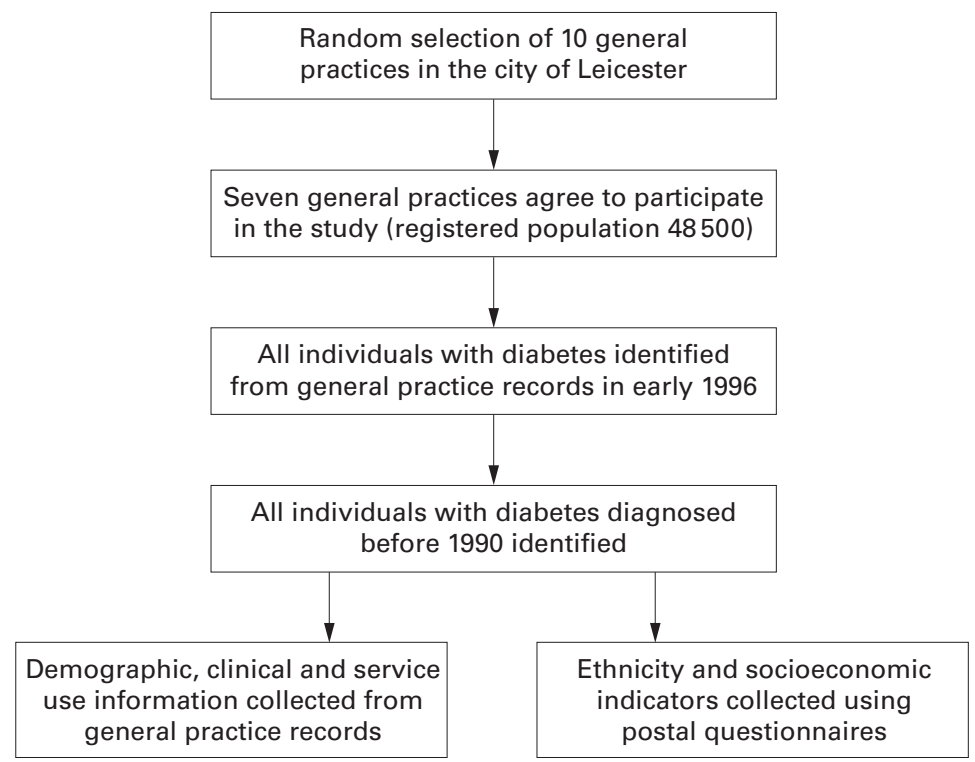

Figure 1 Flow chart of cohort identification and data collection

those who do not have a regular clinical review. Patients with a diagnosis of diabetes who do not access diabetes services are difficult to identify and have not been studied nearly as extensively as those who do attend diabetes clinics.

Detailed individual information was collected on a historical cohort of individuals with diagnosed diabetes for a study of primary and secondary care service use in the city of Leicester which has two acute hospitals with specialist diabetes services. At the time of the study there was no formal shared care and not all GPs offered structured diabetes reviews for their patients. The primary hypothesis addressed using this cohort was that preventive care would reduce hospital admission rates and these findings are reported elsewhere. ${ }^{16}$ It also seemed likely that identifying individual characteristics related to utilisation of preventive services would usefully inform efforts to improve access and reduce variations in service use.

Socioeconomic measures used in studies of health service use are often ecological measures such as the Townsend score, ${ }^{17}$ defined at the small area level using census derived measures. It is unclear whether the relationships observed at an individual level are the same as those found by ecological variables. This study provided an opportunity to examine whether the relationships depended on the choice of socioeconomic variable.

The three questions we wished to address were therefore:

(1) What are the demographic, clinical, and socioeconomic factors associated with attendance at a hospital diabetes clinic or with diabetes review in general practice?

(2) After adjusting for clinical factors, do socioeconomic factors still predict access to the hospital diabetes clinic and to diabetes review in general practice?
(3) Does the relationship observed depend on the choice of socioeconomic variable?

\section{Methods}

The study population was a historical cohort of patients with diabetes registered with a randomly selected sample of general practices. The process of cohort identification and data collection is summarised in fig 1 .

We first identified all general practices in and around the city of Leicester who had access to the same hospital diabetes services. Practical resource limitations and the time available for data extraction limited the size of the study cohort. Ten randomly selected practices were approached and seven practices, with a total registered population of 48500 , agreed to participate in the study. Three practices declined, two because of concerns about confidentiality and a shortage of practice staff and one because they had already conducted a postal survey of their patients with diabetes and did not wish to overburden them with questionnaires.

In the study practices all individuals with diagnosed diabetes were identified by searches of practice registers, medical records, and computerised prescriptions for insulin, oral hypoglycaemic agents, needles and syringes, and blood or urine testing equipment.

\section{OUTCOME VARIABLES}

A routine diabetes review in general practice was defined as one at which at least three of the following were recorded as having been done during a single episode of care: examination of fundi, blood pressure check, foot examination, examination of injection site, weight check, and urinalysis. All visits to the hospital diabetes clinic were identified from the clinic letter in the general practice notes.

\section{EXPLANATORY VARIABLES}

Three types of explanatory variable were collected: demographic variables (age, sex, ethnicity), clinical variables (duration of diabetes, type of treatment, co-morbidity), and socioeconomic variables (postcode, access to a car, house ownership, occupation).

\section{CO-MORBIDITY}

Information on other diagnoses was variably recorded by different general practices. However, all practices used a computer to generate prescriptions for drugs taken long term ("repeat prescriptions"). The number of different drugs prescribed for an individual, excluding treatments for diabetes, was therefore used as a proxy measure for the degree of co-morbidity.

\section{DATA COLLECTION}

Information on age, sex, postcode, duration of diabetes (calculated as the period from the date of diagnosis of diabetes to the end of 1995), and type of diabetes treatment was extracted from general practice records during early 1996. At the same time, information on hospital clinic visits and routine general practice reviews was also extracted. 
Table 1 Characteristics of hospital clinic attendees and non-attendees

\begin{tabular}{|c|c|c|c|}
\hline Variable & $\begin{array}{l}\text { Hospital clinic } \\
\text { attendance }(n=332)\end{array}$ & $\begin{array}{l}\text { No hospital clinic } \\
\text { attendance }(n=288)\end{array}$ & $p$ value \\
\hline Age (years) ${ }^{\star}$ & $61.5(50.2-69.6)$ & $67.3(59.0-76.4)$ & $<0.0001 \dagger$ \\
\hline Duration of diabetes (years) ${ }^{\star}$ & $13.5(9-20)$ & $12.0(9-16)$ & $0.0001 \dagger$ \\
\hline Drugs prescribed $\star$ & $\begin{array}{l}2(0-4) \\
(n=327)\end{array}$ & $\begin{array}{l}2(1-4) \\
(n=279)\end{array}$ & $0.08 \dagger$ \\
\hline Townsend score ${ }^{\star}$ & $2.71(-1.11$ to 5.24$)$ & $2.94(-1.00$ to 5.24$)$ & $0.5+$ \\
\hline Men $\ddagger$ & $190(57)$ & $148(51)$ & 0.19 \\
\hline \multicolumn{4}{|l|}{ Treatment: $\ddagger$} \\
\hline Insulin & $221(67)$ & $34(12)$ & \\
\hline Oral hypoglycaemics & $106(32)$ & $192(67)$ & \\
\hline Diet only & $5(2)$ & $62(22)$ & $<0.00019$ \\
\hline Manual job $\ddagger$ & $51(34)$ & $49(47)$ & 0.039 \\
\hline Home ownership $\ddagger$ & $204(75)$ & $133(61)$ & $0.002 \Phi$ \\
\hline Access to car $\ddagger$ & $152(56)$ & $90(41)$ & $0.001 \rrbracket$ \\
\hline \multicolumn{4}{|l|}{ Ethnicity: $\ddagger$} \\
\hline White & $129(47)$ & $92(41)$ & \\
\hline Indian & $116(42)$ & $121(55)$ & \\
\hline Other & $31(11)$ & $9(4)$ & 0.002 ब \\
\hline
\end{tabular}

^Values are median (interquartile range).

†Mann Whitney U test.

$\ddagger$ Values are number $(\%)$

ฯ $\chi^{2}$ test.

Table 2 Odds ratios associated with hospital clinic attendance

\begin{tabular}{llll}
\hline Variable & Crude odds ratio & $\begin{array}{l}\text { Adjusted } \\
\text { confidence interval) }\end{array}$ & p value \\
\hline Townsend score & 0.99 & $1.00(0.97$ to 1.03$)$ & 1.0 \\
Access to car & 1.35 & $1.34(1.06$ to 1.71$)$ & 0.02 \\
Home ownership & 1.36 & $1.48(1.14$ to 1.58$)$ & 0.003 \\
Non-manual occupation & 1.32 & $1.56(1.09$ to 2.24$)$ & 0.02 \\
Non-white ethnicity & 0.90 & $0.99(0.77$ to 1.28$)$ & 0.9 \\
\hline
\end{tabular}

${ }^{\star}$ Adjusted for age, treatment type, duration of diabetes and co-morbidity.

Postal questionnaires were sent to the entire cohort in up to three languages (English, Gujarati and Punjabi). The question about ethnic origin used the census categories and these were then combined to give three categories: "white", "Indian" and "other" (most respondents indicated they were "white British" or "Indian"). These were further combined to compare "white" and "non-white" subjects. Individual questions were asked about access to a car, house ownership, and occupation.

TOWNSEND SCORES

Postcodes were linked to wards, using a computerised postcode directory, in order to calculate Townsend scores using 1991 census data. The Townsend score is an indicator of material deprivation which combines four variables: unemployment, car ownership, house ownership, and overcrowding. The higher the score, the greater the degree of relative material deprivation.

DATA ANALYSIS

Only individuals who had a diagnosis made before 1990 were included in the analyses. Patients who died before 1995 were excluded because the period for which access to services could be studied would have been less than for survivors, and because information on individual socioeconomic variables was only available for survivors who completed questionnaires.

The two outcomes studied were "having attended a hospital diabetes clinic at least once between 1990 and 1995", and "having had a routine diabetes review in general practice at least once between 1990 and 1995". The rela- tionships between characteristics of the cohort and hospital clinic attendance and general practice review were analysed separately. Individual variables associated with service use were identified using Mann-Whitney $U$ tests for continuous variables and $\chi^{2}$ tests for categorical variables. The clinical explanatory variables were also simultaneously entered into a logistic regression model. Individual socioeconomic variables were separately added to this model to determine whether they were still associated with service use outcomes after adjusting for clinical differences, using a significance level of less than 0.05 . All variables were included in the model as categorical variables except duration of diabetes, number of non-diabetes drugs, and Townsend score (and recoding these variables as categorical variables produced similar results).

The study was approved by the Leicestershire Health Authority local research ethics committee.

\section{Results}

A total of 1094 individuals with diabetes were identified; unadjusted prevalence varied between practices from $1.3 \%$ to $3.5 \%$. All individuals with diabetes diagnosed by 1990 and surviving until the end of 1995 were included in the analyses $(n=620) ; 124(20 \%)$ had at least one recorded diabetes review in general practice and $332(54 \%)$ attended a hospital diabetes clinic at least once. Fifty one $(8 \%)$ had both a review in general practice and attended a hospital clinic at some time in the six years of the study and 215 (35\%) had neither. For some of the following analyses the denominators are reduced by incomplete data, either because ward Townsend scores were unavailable ( $\mathrm{n}=14$ ) or because questionnaires were not returned or were returned incomplete (response rate $79 \%$ ).

\section{FACTORS RELATED TO HOSPITAL CLINIC} ATTENDANCE

Table 1 shows the relationship between potential explanatory variables and attendance at a hospital diabetes clinic. Hospital clinic attendance was associated with younger age, a longer duration of diabetes, and treatment with insulin. A non-manual job, ethnic origin other than Indian, access to a car, and home ownership all increased the likelihood of clinic attendance, yet the Townsend score was not related to clinic attendance.

Multivariate logistic regression (table 2) showed that a non-manual occupation, access to a car, and home ownership all increased the likelihood of clinic attendance after adjusting for clinical factors.

FACTORS RELATED TO GENERAL PRACTICE REVIEW Table 3 shows that increasing age, decreasing co-morbidity, and ethnic origin other than Indian were all associated with an increased likelihood of having been seen at least once for a routine diabetes review in general practice. Diabetes treatment and duration of diabetes were not related to the likelihood of being seen. After adjustment for morbidity, a lower 
Table 3 Characteristics of general practice review attendees and non-attendees

\begin{tabular}{|c|c|c|c|}
\hline Variable & $\begin{array}{l}\text { General practice review } \\
\text { median (interquartile } \\
\text { range) }(n=124)\end{array}$ & $\begin{array}{l}\text { No general practice } \\
\text { review median } \\
\text { (interquartile range) } \\
(n=496)\end{array}$ & p value \\
\hline Age (years) ${ }^{\star}$ & $69.7(58.7-77.1)$ & $62.8(54.6-72.0)$ & $<0.0001 \dagger$ \\
\hline $\begin{array}{l}\text { Duration of diabetes } \\
\text { (years) }^{\star}\end{array}$ & $13(9-18)$ & $12(9-18)$ & $0.8+$ \\
\hline Drugs prescribed $\star$ & $\begin{array}{l}2(0-3) \\
\mathrm{n}=120\end{array}$ & $\begin{array}{l}2(1-5) \\
\mathrm{n}=486\end{array}$ & $0.0006+$ \\
\hline Townsend score ${ }^{\star}$ & $-1.01(-2.70$ to 2.85$)$ & $3.26(-0.21$ to 5.42$)$ & $<0.0001 \dagger$ \\
\hline Men $\ddagger$ & $67(54)$ & $271(55)$ & 0.99 \\
\hline \multicolumn{4}{|l|}{ Treatment: $\ddagger$} \\
\hline Insulin & $45(36)$ & $210(42)$ & \\
\hline Oral hypoglycaemics & $62(50)$ & $236(48)$ & \\
\hline Diet only & $17(14)$ & $50(10)$ & $0.3 \pi$ \\
\hline Manual job $\ddagger$ & $28(35)$ & $72(41)$ & $0.4 \pi$ \\
\hline Home ownership $\ddagger$ & $74(69)$ & $263(69)$ & $1.0 \%$ \\
\hline Access to carł & $59(55)$ & $183(48)$ & $0.2 \pi$ \\
\hline \multicolumn{4}{|l|}{ Ethnicity: $\ddagger$} \\
\hline White & $99(89)$ & $122(32)$ & \\
\hline Indian & $1(1)$ & $236(61)$ & \\
\hline Other & $11(10)$ & $29(8)$ & $<0.00019$ \\
\hline
\end{tabular}

*Values are median (interquartile range).

† Mann Whitney U test.

$\ddagger$ Values are number $(\%)$

$\llbracket \chi^{2}$ test.

Table 4 Odds ratios associated with general practice review

\begin{tabular}{llll}
\hline Variable & $\begin{array}{l}\text { Crude odds } \\
\text { ratio }\end{array}$ & $\begin{array}{l}\text { Adjusted } \\
\text { confidence interval) }\end{array}$ & p value \\
\hline Townsend score & 0.80 & $0.81(0.76$ to 0.86$)$ & $<0.0001$ \\
Access to car & 1.14 & $1.24(0.98$ to 1.57$)$ & 0.08 \\
Home ownership & 1.00 & $0.96(0.75$ to 1.24$)$ & 0.8 \\
Non-manual occupation & 1.13 & $1.04(0.77$ to 1.41$)$ & 0.8 \\
Non-white ethnicity & 0.24 & $0.25(0.18$ to 0.34$)$ & $<0.0001$ \\
\hline
\end{tabular}

${ }^{\star}$ Adjusted for age, treatment type, duration of diabetes, and co-morbidity.

Townsend score (less material deprivation) and being white were found to be related to an increased chance of being seen in general practice (table 4). However, individual socioeconomic characteristics - for example, manual occupation, access to a car, or home ownership-were not statistically significant predictors of a review in general practice.

\section{Discussion}

Attendance at a hospital clinic is associated with younger age, longer duration of diabetes, and treatment with insulin whilst attendance for a diabetic review in general practice is associated with older age and lower co-morbidity. These associations reflect the different case mix seen by hospital clinics and general practice.

After adjustment for these case mix differences, Townsend scores and ethnicity still predict the likelihood of review in general practice, while only individual markers of relative deprivation predict attendance at a hospital clinic.

Individual general practices and practice characteristics were not included as explanatory variables. It is more likely that, since deprivation and ethnicity may determine place of residence and therefore the general practice with which an individual is registered, as a variable general practice would lie on a "causal pathway" between individual characteristics and pattern of care rather than being an independent explanatory variable. The general practice with which an individual was registered was closely related to other variables which are geographically clustered including ethnicity, Townsend score, and individual socioeconomic indicators.

The most striking findings are the differences in odds ratios between Townsend scores and individual socioeconomic variables for both outcomes. The likelihood of a general practice review is related to the ward Townsend score but not to individual variables (some of which make up part of the Townsend score). Conversely, the likelihood of attending a hospital clinic is related to individual variables but not to Townsend scores. These are examples of the "ecological fallacy"-that is, relationships between deprivation and service use for small areas may well be different from the relationships found when individuals are studied. Using postcodes may result in some misclassification of Townsend scores. ${ }^{18}$ However, since the misclassification would be consistent, this cannot contribute to an explanation of the different relationships between Townsend scores and service use for primary and secondary care.

The difference between the factors related to general practice and hospital attendance reflect differences in the factors responsible for differential access to primary and secondary care. For general practice the major issue may be one of service organisation and access in relatively deprived areas. It is known that, nationally and locally, general practices in more deprived areas were slower to take up additional payments for structured diabetes care. ${ }^{19} 20$ Practices with a high proportion of patients of Indian origin will have a high prevalence of diabetes, which is also associated with less structured diabetes care. ${ }^{19}$ If structured care is available locally, individual characteristics may not have much influence on attendance. In fact, if general practice is included as a variable in the analysis, the relationship with the Townsend score is greatly weakened, implying that the practice characteristics are part of the "causal pathway" between living in a deprived area and poorer access to diabetes reviews in general practice.

For hospital clinic attendance the picture is different. Overall, patients from deprived areas and wealthier areas are equally likely to attend the hospital clinic. Because individuals in relatively deprived inner city areas may have equally as high rates of attendance at a hospital clinic as those from more affluent areas and less access to cars for transport, this might suggest that access to a car does not influence the chances of diabetic patients attending a hospital clinic. However, within an urban area, at an individual level access to a car is associated with an increased chance of attending a hospital clinic (table 2). Thus, although the Townsend score data might suggest that there is not a link between deprivation and lack of access to the hospital clinic at ward level, at an individual level such an association can exist.

These results highlight the possibility that small area information can hide inequalities at the individual level. They suggest that, while the reasons for inequality in access to diabetes care in general practice may be organisational, the reasons for inequality in access to second- 
ary care may be more closely linked to individual characteristics.

The factors which determine whether an individual attends a hospital diabetes clinic or attends for review in general practice are complex and depend on the structure of services and many individual characteristics of healthcare providers and patients themselves. Qualitative studies of diabetes care organisation and of the views of patients and providers are needed to unravel the associations between relative material deprivation and lack of access to services. Better understanding of the reason for inequalities in access to services can inform the development of intervention studies which are needed to identify effective ways of improving access to effective health care for all people with diabetes.

The authors thank Lucy Smith for providing the Townsend scores. Mike Drucquer, Lucy Smith, Allen Hutchinson and Nick Payne all commented on an earlier draft. We are grateful to the participating general practices and patients without whose involvement the study would not have been possible.

Funding: ECG was supported by an MRC/Trent Training Fellowship in Health Services.

1 UK Prospective Diabetes Study (UKPDS) Group. Intensive blood glucose control with sulphonylureas or insulin compared with conventional treatment and risk of complications in patients with type 2 diabetes (UKPDS 33). Lancet 1998;352:837-53.

2 UK Prospective Diabetes Study (UKPDS) Group. Tight blood pressure control and risk of macrovascular and
microvascular complications in type 2 diabetes: UKPDS 38. BM7 1998;317:703-13.

3 Yudkin JS, Boucher BJ, Schopflin KE, et al. The quality of diabetic care in a London health district. $\mathcal{F}$ Epidemiol Comdiabetic care in a London hea

4 Williams DRR, Munroe C, Hospedales CJ, et al. A three-year evaluation of the quality of diabetes care in the three-year evaluation of the quality of diabetes care in the
Norwich Community Care Scheme. Diabetic Med 1990;7: Norwich

5 Burrows PL, Gray PJ, Kinmonth A, et al. Who cares for the patient with diabetes? Presentation and follow-up in seven Southampton practices. $\mathcal{F}$ R Coll Gen Pract 1987;37:65-9.
6 Goyder EC, McNally PG, Drucquer M, et al. Shifting care for diabetes from secondary to primary care, 1990-95: review of general practices. BMF 1998;316:1505-6.

7 McNally PG, Burden AC, Swift PGF, et al. The prevalence and risk factors associated with the onset of diabetic nephropathy in juvenile-onset (insulin-dependent) diabetics diagnosed under the age of 7 years in Leicestershire 19301985. O f Med 1990;76:831-44.

8 Payne JN, Saul C. Variations in the use of cardiology services in a health authority: comparison of coronary artery revascularisation rates with the prevalence of angina and coronary mortality. BMF 1997;314:257-61.

9 Chapple A, Gatrell A. Variations in use of cardiac services in England: perceptions of general practitioners, general physicians and cardiologists. 7 Health Serv Res Policy 1998;3:153-8.

10 Van der Meer JBW, van den Bos J, Mackenbach JP. Socioeconomic differences in the utilisation of health services in a Dutch population: the contribution of health status. Health Policy 1996;37:1-18

11 Goddard M, Smith P. Equity of access to health care. York: NHS Centre for Reviews and Dissemination, 1998.

12 Kelly WF, Mahmood R, Kelly MJ, et al. Influence of social deprivation on illness in diabetic patients. BMF 1993;307: 1115-6.

13 Connolly VM, Kesson CM. Socioeconomic status and clustering of cardiovascular disease risk factors in diabetic patients. Diabetes Care 1996;19:419-22.

14 Chaturvedi N, Stephenson JM, Fuller JH, EURODIAB IDDM Complications Study Group. The relationship between socioeconomic status and diabetes control and complications in the EURODIAB IDDM Complications Study Diabetes Care 1996;19:423-30.

15 Kelly WF, Mahmood R, Turner S, et al. Geographical mapping of diabetic patients from the deprived inner city shows ess insulin therapy and more hyperglycaemia. Diabetic Med 1994;11:344-8.

16 Goyder EC, Spiers N, McNally PG, et al. Do diabetic clinic attendees stay out of hospital? A matched case-control study. Diabetic Med 1999;16:687-91.

17 Townsend P, Phillimore P, Beatie A. Health and deprivation: inequality and the north. London: Croom Helm, 1988.

18 Collins SE, Haining RP, Bowns IR, et al. Errors in postcode to enumeration district mapping and their effect on small area analyses of health data. $f$ Public Health Med 1998;20:325-30.

19 Goyder EC, Jennings S, Botha JL. Why don't all general practices offer structured diabetes care? A comparison of practices that do not with those that do. Public Health 1996;110:357-60.

20 Leese B, Bosanquet N. Change in general practice and its effects on service provision in areas with different socioeconomic characteristics. BMF 1995;311:546-50. 